\title{
LA TRADICIÓN DE LOS BESTIARIOS FRANCESES Y SU INFLUENCIA EN LA PENÍNSULA IBÉRICA (c) (1) (9)
}

Llúcia Martín PASCUAL ${ }^{1}$

Universidad de Alicante

\section{Resumen}

Este trabajo pretende realizar, en primer lugar, una descripción de los textos de los bestiarios conservados en francés en verso y en prosa, éstos últimos tanto de temática moral como amorosa. Una vez realizada esta descripción, observaremos como se ha producido la evolución de la materia animalística, hecho que propicia el cambio de perspectiva de unos textos religioso-morales a otros amorosos. Finalmente, intentaremos demostrar que los bestiarios en prosa franceses, tanto amorosos como morales influyen en la configuración de los bestiarios toscanos, fuente a su vez de los bestiarios catalanes.

Palabras clave

Bestiarios, Physiologus, tradición animalística, bestiarios franceses, bestiarios catalanes, bestiarios amorosos

\begin{abstract}
In this work we describe, first, French Bestiaries written in verse and prose at the Middle Ages. We can find moralizing texts and also loving texts in French prose bestiaries. The second objective of this paper is to analyze the evolution of the animalistic traditions and the change from religious and moralizing texts into a loving works. Finally we are going to see the influence of French bestiaries (moralizing and loving texts) in the structure of Tuscan bestiaries and its translation into Catalan language.
\end{abstract}

\section{Key words}

Bestiary, Physiologus, animalistic tradition, French bestiaries, Catalan bestiaries, loving bestiaries.

Las múltiples manifestaciones literarias que se desarrollaron en la Europa Medieval haciendo uso de las lenguas románicas y que se conocen como bestiarios son en realidad textos de carácter muy heterogéneo. Las diferencias son tanto relativas a los contextos lingüísticos de producción como a la intencionalidad de estas composiciones: mientras que los textos franceses se acercan más a las versiones latinas del Physiologus, con una apreciación alegórica de los animales y un desarrollo narrativo que recuerda a los primeros roman en verso, los textos toscanos se configuran como manuales de conducta. No podemos, sin embargo, dejar de hacer constar los bestiarios amorosos, otros de contenido puramente místico como el Bestiario valdés y ciertos textos con descripciones animales pero sin contenido simbólico. ${ }^{2}$ A esto hay que añadir que no conserva-

1 Universidad de Alicante. Correo: 1lucia.martin@ua.es. Recibido: 17-03-2014. Aceptado: 26-07-2014

2 Dejamos a un lado los textos enciclopedicos cuyo valor es puramente "científico" y no incluyen simbología, aunque las descripciones de los animales que aparecen en las enciclopedias se asemejan a las de los bestiarios, algunas incluso se remontan a los antiguos Physiologi. En la Península ibérica fue muy conocido el tratado de Brunetto Latini, Li livres dou Tresor, traducido tanto al castellano como al aragonés y al catalán. 
mos textos de bestiarios en castellano ${ }^{3}$ aunque la simbología animal era bien conocida, mientras que en portugués existe un Livro das Aves, traducción del libro primero o Aviarium de la enciclopedia atribuida a Hugo de Foulloi, De Bestiis et allis rebus.

\section{LOS BESTIARIOS FRANCESES EN VERSO}

Cronológicamente, los bestiarios franceses son los más antiguos pues datan de los siglos XII y XIII, y los más vinculados con la tradición latina, aunque presentan entre ellos enormes diferencias (McCulloch 1962). ${ }^{4}$ Los más conocidos son los Bestiarios de Guillaume le Clerc (GC) y Pierre de Beauvais (PB), junto con el de Philippe de Thaon (PT) y el de Gervaise (Ge). Aún existe otro texto de dimensiones reducidas conocido como Poème moralisé sur les propietés des choses, descrito por Gaston Raynard el 1885 y que trata las propiedades de plantas y animales asimiladas a la figura de Santa María. $^{5}$

El texto de Philippe de Thaün, el más primitivo de los cuatro, se remonta al siglo XII según sus editores (Mann 1884, Walberg 1900). ${ }^{6}$ El estudio de Florence Mc Culloch $(1962,47-56)$, indica que el texto procede de Normandía y es la primera versión romance del Physiolgus latino, concretamente de la versión B, con adiciones de las Etimolgiae de san Isidoro, lo que constituye una versión que la estudiosa denomina B-Is. El Bestiaire consta de 3195 versos, el nombre del autor aparece en el primer verso identificado con el poeta normando, autor también de una obra conocida como Comput y de un lapidario. Thaün dedica su obra a «Aaliz, reine est d'Englaterre» que puede referirse a Aelis de Louvain, esposa de Enrique I de Inglaterra, documentada el 1121 o bien a Elionor de Aquitania, reina de Inglaterra desde 1152 a $1204 .^{7}$ El bestiario se con-

3 Excepto un texto tardío y de carácter enciclopédico conocido como el Bestiario de Juan de Austria, descubierto en el Monasterio de Santa María de la Vid (Fradejas Rueda 2005, 127-140).

4 La autora establece varias familias latinas procedentes del Physiologos griego (Sbordone, 1936, Zambon y Fisiólogo 1999) y localiza los testimonios más importantes. Según su clasificación, el Physiologus latino tiene cuatro versiones A, B, C e Y, de las cuales B, Y son las más importantes (Carmody, 1941, Villar \& Docampo 2003). La versión B (Carmody 1939) sufrió diversas adiciones procedentes de las Etimologiae de san Isidoro (versión B-Is) y del De bestiis et aliis rebus (versión H), una enciclopedia patrística que incrementa considerablemente los capítulos sobre animales y de la que derivan bestiarios latinos de grandes dimensiones (manuscritos de los escriptorios ingleses Oxford, Cambridge...) que además facilitó la redacción enciclopedias y tratados naturalísticos.

5 Por ejemplo la pantera: «la panthère si est Marie qui d'atrempance fu garnie» (Raynard 1885, 442-484). 6 Hay una edición modernizada de Luigina Moroni de 1996 y una edición crítica de Shannon Hogan Cottin-Bizonne de 2005.

7 A favor de la tesis que el bestiario fue escrito en la corte de Enrique I tenemos el trabajo de Alexandre H. Kappe $(1944,59)$ según el cual el rey tenía un interés notable por la zoología como demuestra su gusto por la caza y por la colección de animales exóticos. Más tarde tomó fuerza la tesis de identificar Aelis con Elionor de Aquitania (Dupuis \& Louis 1988). Cualquiera de las dos reinas pudo haber mandado traducir al francés una versión latina del Physiologus. La Normandía francesa se encuentra muy vinculada a los centros de saber del llamado "renacimiento inglés", que produjeron una serie de textos latinos de bestiarios y un interés por la naturaleza en las obras de Neckam o Cantimpré. 
serva en tres manuscritos, dos de ellos ilustrados: el de la Kongelige Bibliotek, Gl. kgl. S. $34668^{\circ}$, un rico manuscrito del siglo XIV en pergamino; el códice del Merton College Library, MS. 249 datado en el siglo XIII y con ilustraciones más sencillas; y un tercero sin ilustraciones localizado en la British Library, Cotton Nero A. v, posiblemente el más antiguo, datado en el siglo XII. ${ }^{8}$ Contiene 34 descripciones de animales y cuatro propias del lapidario que se suceden con un pequeño hilo argumental y aludiendo constantemente a dos autoridades Physiologus y san Isidoro (Ysidres dit).

El bestiario de Gervaise es un texto de 1278 versos datado en siglo XIII que contiene 29 bestias y según este misterioso autor, se trata de un original traducido de «Johanz Boche d'Or nomnez, Chisostomus rest apelez» (Meyer 1872, 426; Moroni 1996; McCulloch 1962, 41-44 y 55-56). Se conserva únicamente en el manuscrito de la British Library, Additional MS 28260 y es uno de los textos más desconocidos del que tampoco podemos señalar una relación con el hipotético original griego, los Dicta Chrisostomi. La simbología religiosa que presenta es la habitual: distribución entre los animales que representan Jesucristo y los que representan el diablo, además incluye varias referencias a María con una apología a su virginidad.

La obra de Guillaume le Clerc o de Normandie consta de 3426 versos, es el bestiario de mayor extensión entre los franceses en verso y obtuvo una gran popularidad como demuestran los más de 20 testimonios manuscritos conservados en diferentes Bibliotecas. ${ }^{9}$ Sin embargo, esta popularidad no se materializa en estudios o ediciones actuales, ya que solo contamos con ediciones antiguas (Mann 1888, Hippeau 1852, Reisch 1890), una traducción de George Druce 1938 y una versión moderna de Gabriel Bianciotto de 1980. El estudio más extenso realizado de este texto, hoy por hoy aún vigente, es el trabajo de Robeert Reinsch el 1890, que si bien no utiliza todos los testimonios manuscritos en su edición, dedica extensos apartados a establecer una filiación con la versión del Physiologus latino que puede haber sido su fuente y la vinculación con el tratado De bestiis et aliis rebus, del que procederían las adiciones. McCulloch (1962, 57-58) data la redacción a inicios del siglo XIII basándose en la lectura de los versos 10-13 que parece referirse a la época de constantes luchas con Inglaterra durante el reinado de Felipe II de Francia (1165-1223).

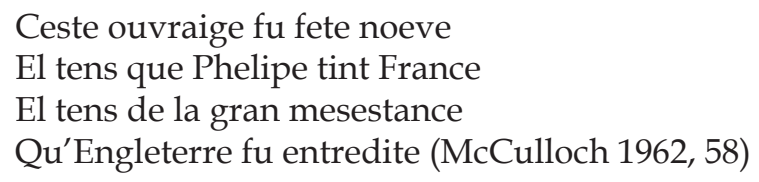

Más aún, en los versos 2707-2717 el autor añade que el libro se escribió dos años después que Inglaterra sufriera el interdicto del Papa Inocencio III en 1208, por lo tanto

8 Obtenemos esta información de McCulloch $(1962,48-49)$ y los manuscritos digitalizados de bestiary. ca, a través de la URL http:/ / bestiary.ca/biblio.htm (consultada el 10 de marzo de 2014)

9 Información y descripción de los manuscritos en el recurso virtual bestiary.ca a través de la URL http://bestiary.ca/prisources/psmanu1097.htm (consultada el 10 de marzo de 2014). 
la posible redacción del bestiario se fijaría en torno a 1210:

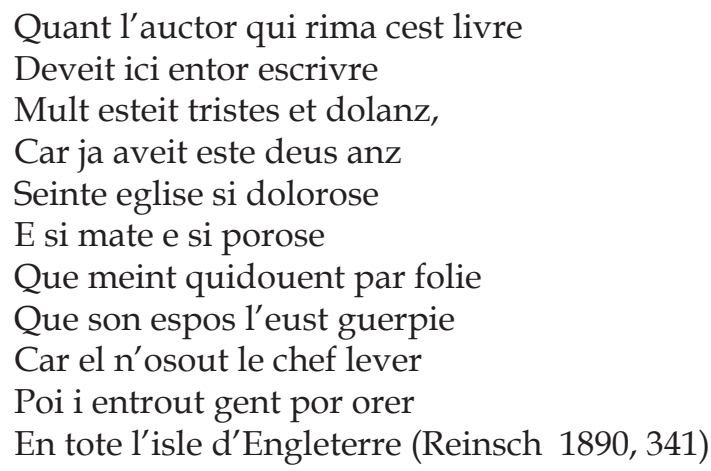

La voz del autor y las constantes referencias personales son habituales en este texto: « le clerc fu nez de normandie, / qui auctor est de ce roman, / or est dit li normanz ». ${ }^{10}$ Este estilo más directo y coloquial resulta adecuado a la finalidad de la obra: dar unas pautas de comportamiento de acuerdo con las normas cristianas. Contiene 35 especies animales, según la edición Reinsch, que coinciden con los capítulos y el orden de una de las versiones del Physiologus latino, sin embargo, al contrario que ocurría con el texto de Thaün, no encontramos referencias a una posible autoridad del Physiologus, lo que convierte este bestiario en uno de los más singulares de la tradición francesa.

En el siguiente cuadro reproducimos los contenidos de los textos de Thaün, Gervaise y Guillaume le Clerc

\begin{tabular}{|c|c|c|}
\hline $\begin{array}{c}\text { Bestiaire de Philippe } \\
\text { de Thaün }\end{array}$ & Gervaise & Guillaume le Clerc \\
\hline $\begin{array}{c}\text { Incipit (dedicatoria a } \\
\text { Aeliz de Louvaine) }\end{array}$ & $\begin{array}{c}\text { Incipit (traducción del } \\
\text { Jehan Bocche d'Or nomnez) }\end{array}$ & $\begin{array}{c}\text { Incipit (autoría y dedi- } \\
\text { catoria ) }\end{array}$ \\
\hline Leun & Lion & Lion \\
\hline Vulpis & Panthere & Aptalos \\
\hline Monoceros & Unicorn & Perres de feu \\
\hline Onager & Idres et Cocadril & Serre \\
\hline Panter & Serene & Caladrius \\
\hline Singes & Centaurus & Pellican \\
\hline
\end{tabular}

10 Conocemos más obras de este autor como Le Besant de Dieu; Romanz de sainte Marie Magdalein; Les Joies Nostre Dame y La vie de Tobie. Tambien se le atribuye un roman conocido como Roman de Fergus de contenido paródico. 


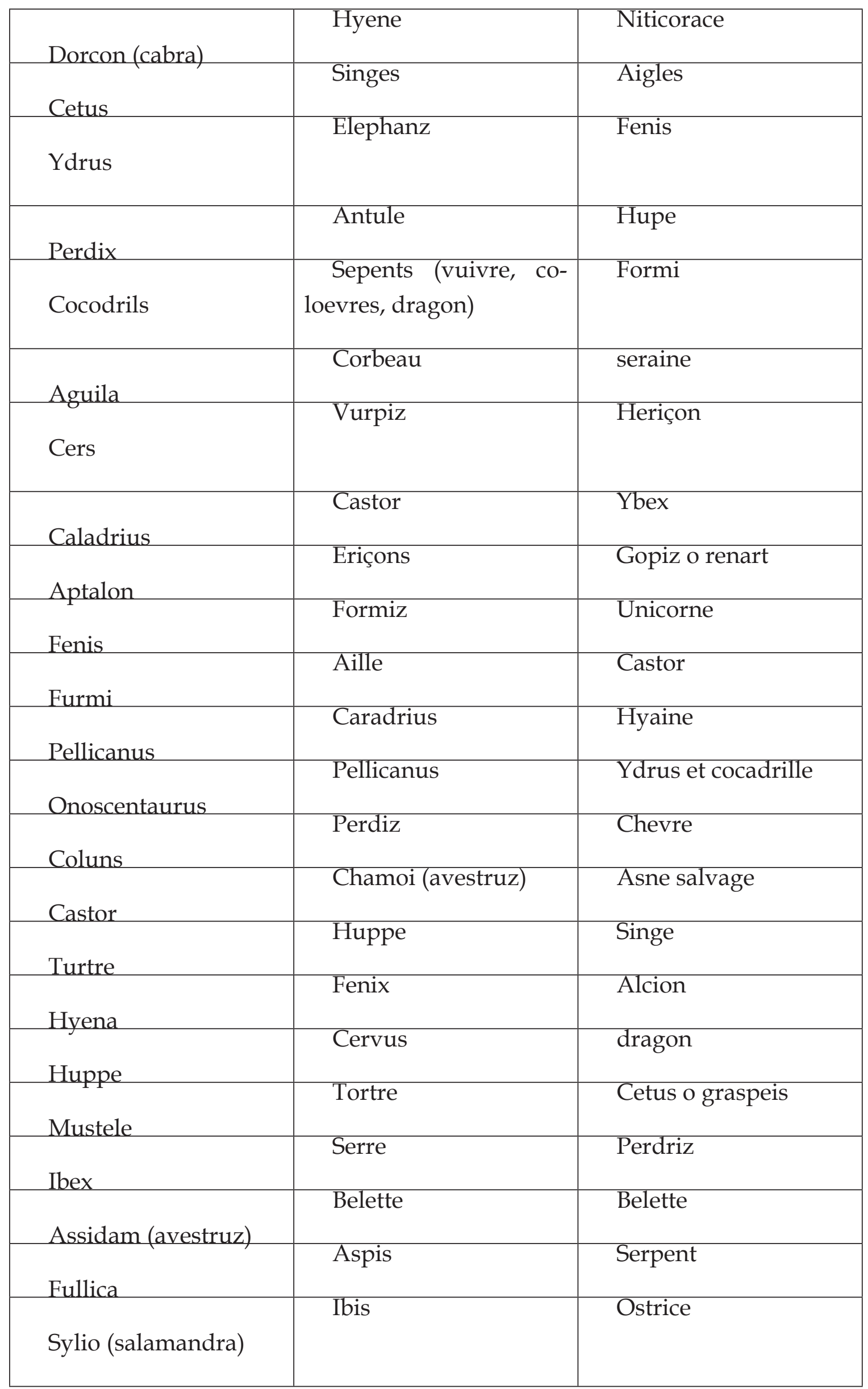




\begin{tabular}{|c|l|l|}
\hline Nicticorax & & Turtre \\
\hline Serena & & Salamandre \\
\hline Turrobolem & & Coloms et paradixon \\
\hline Elefant & & Olifant et mandra- \\
\hline Adamas & goire \\
\hline Aspis & & Diamanx \\
\hline $\begin{array}{c}\text { Duze pierres }(\text { del } \\
\text { Apocalipsis })\end{array}$ & & \\
\hline Serra & & \\
\hline Heriçun & & \\
\hline Explicit & & \\
\hline
\end{tabular}

En esta relación observamos que las especies animales son las mismas aunque el orden es diferente y depende de la versión latina que se conoce como fuente. En el caso de Philippe de Thaün, el original podría tratarse de un manuscrito de la versión B del Physiologus concretamente el texto de la Bodleian Library, MS. Laud Misc. 247, con adiciones de San Isidoro. Por otra parte el texto de Guillaume le Clerc parece derivar, según McCulloch $(1962,61)$ del manuscrito latino British Library Royal 2.C.XII, en cambio Reinsch, por su parte, vincula que la fuente es el tratado de Hugo de Folloi, De bestiis et aliis rebus, concretamente el libro II, cuya estructura es semejante al Physiologus latino. En cualquier caso, se trata de textos próximos a un original latino con presencia de adiciones procedentes de las Etimologías de san Isidoro y posiblemente cercanos a los textos patrísticos que describen a los animales, haciendo una exégesis del libro del Génesis pero al mismo tiempo con una voluntad de descripción naturalística, que con el tiempo dará lugar a las extensas enciclopedias medievales.

\section{LOS BESTIARIOS EN PROSA: PIERRE DE BEAUVAIS I RICHARD DE FOUR-} NIVAL

El bestiario atribuido a Pierre de Beauvais contiene adiciones procedentes de obras enciclopédicas como el De bestiis et aliis rebus, y posiblemente de los extensos bestiarios latinos que se compilaron en los escritorios ingleses de Oxford y Cambridge en los 
siglos XII y XIII. ${ }^{11}$ Más aún, el Bestiaire de Beauvais es uno de los textos más enigmáticos, sorprendentes y desconocidos del panorama medieval, como ya advertía Florence McCulloch (1962: 62). Actualmente la crítica acepta dos versiones, una larga y otra corta, de la primera se conoce la transcripción de Cahier-Martin de 1850, y recientemente la tesis de Craig Baker (2010); de la segunda podemos consultar la edición de Guy Mermier de 1982 (Rebuffi 1978: 34-65; Bianciotto 1980). La versión corta se redactó primero, hacia 1206, siguiendo bastante de cerca un original latino del Physiologus, con un total de 38 capítulos, mientras que la versión larga, de $71^{12}$ capítulos, no puede ser fechada hacia 1218 como se creía, añade 34 capítulos más y altera el orden de los capítulos ya existentes en la versión corta. Estas son las conclusiones de las recientes investigaciones de Craig Baker (2005, 1-29), quien además cuestiona la autoría de esta versión al autor conocido como Pierre de Beauvais aunque aparece este nombre en el proemio de la obra, si bien las adiciones procederían de otra obra, la Imago Mundi de Honorius de Autun (Angremy 1983, 316):

[Prohemio] Il est apeles ainsy pour ce que il divisse de la nature des bestes et oyseaux car toutes les criatures que Dieu crea in terre il les crea pour l'omme et pour prendre exemples en elles du foy et de creance, et fut ce livre translate de latin en françois et y mist grand travail et gran paine Pierres qui voulantiers lu fist par le commandament de l'evesque Philippon, cuers en qui service aut pris mis. ${ }^{13}$

Además de las versiones del bestiario, se atribuye al desconocido Pierre, una serie de obras religiosas y hagiográficas así como dos leyendas pseudohistóricas conocidas como Olimpyade y Voyage en Orient de Charlemagne (Berkey 1961, Walpole 1949).

Ya se trate de obra original o no de Pierre de Beauvais, nos centramos en la versión larga, la más interesante por los capítulos adicionales reflejados en un texto animalístico por primera vez y, por tanto, alejado de las versiones latinas del Physiologus. La crítica consideró durante un tiempo que esta versión larga parece ser el precedente de bestiarios posteriores de naturaleza didáctica, también escritos en prosa, como pueden ser el Bestiaire d'amour (Segre 1957), o los bestiarios de la tradición toscana, con los que coinciden algunos animales novedosos incluidos por primera vez en el bestiario

11 Nos referimos a textos como el Bestiario de Oxford (ms Ashmole 1511, facsímil 1983), una de las versiones más extensas que hemos constatado y que constituye una auténtica enciclopedia con un intento de clasificación de los animales y extraordinarias miniaturas. Otro de los manuscritos importantes de este grupo latino es el texto de la Universidad de Cambridge, ms. II, 4, 26.

12 Generalmente se atribuyen 71 capítulos ya que McCulloch, basándose en el manuscrito Reginensis 1323 de la Biblioteca Vaticana así lo constata, sin embargo hay algunas oscilaciones entre los manuscritos y el editor señala versiones que contienen un capítulo más dedicado al hombre (Baker 2010, 11-13).

13 En este proemio, el copista asegura que el libro fue traducido del latín por un desconocido Pierres, con gran afán. Añade que prefirió no escribirlo en verso, sino como el Physiologus latino y pretende con su obra hacer sentir las "naturas" de bestias y aves y su sentido espiritual. Inicia la descripción con el león que es el rey de todas las bestias: «sy fait bon a ouir et a entender ea retener les natures de lui ». Cada capítulo animal va precedido de una rúbrica, a diferencia de los bestiarios en verso en los que no había diferenciación entre capítulos sino una concatenación argumental. 
de Beauvais. Actualmente, nuevas investigaciones datan la composición de la versión larga de Beauvais entre 1246 y 1268, por lo tanto, posterior al Bestiarie atribuido a Richard de Fournival, de quien Beauvais copiaría algunos fragmentos (Baker 2010, 2728).

Conocemos 6 manuscritos conservados de esta versión larga, cuatro de los cuales ya constatados por McCulloch $(1962,62)$. Recientemente se han descubierto dos manuscritos, uno de ellos fragmentario, ambos por Abeele y Baker. ${ }^{14}$ Otra diferencia respecto los Bestiarios de Thaün y Clerc radica en que estos se presentan como una pequeña narración donde se suceden las características animales. En cambio Beauvais concibe su bestiario como una especie de diccionario con apartados diferenciados e independientes de cada animal. En general, el listado de especies reproduce animales -y algunas piedras- ya conocidos por las versiones latinas del Physiologus pero también se incluyen otros animales hasta ahora desconocidos.

El contenido de las dos versiones del Bestiaire de Pierre de Beauvais es el siguiente:

\begin{tabular}{|c|c|}
\hline $\begin{array}{l}\text { Versión corta (según ms. } \\
\text { BNF 834) }\end{array}$ & $\begin{array}{l}\text { Versión larga (segun ms. Vat- } \\
\text { Reg. 1323) }\end{array}$ \\
\hline Lyon & $\begin{array}{l}\text { 2r Lyon. Reproduce la cita bí- } \\
\text { blica del Génesis Jacob quant il } \\
\text { beinst Judas son fils, que también } \\
\text { aparece en el Physiologus. }\end{array}$ \\
\hline Antula & $\begin{array}{l}\text { 3r Antulla. Según el orden del } \\
\text { antiguo Physiologus, es la segun- } \\
\text { da bestia del tratado. Se trata de } \\
\text { un animal conocido como anta- } \\
\text { lop, autolopos, en algunos casos } \\
\text { traducido como antílope cuya } \\
\text { característica principal es que } \\
\text { posee dos cuernos que simboli- } \\
\text { zan el Antiguo y el Nuevo } \\
\text { Testamento }\end{array}$ \\
\hline De 11 pierrez ardanz & $\begin{array}{l}\text { 3r Serra. Animal marino con } \\
\text { una cresta poderosa capaz de } \\
\text { destruir los barcos. }\end{array}$ \\
\hline De la serre & $\begin{array}{l}3 \mathrm{v} \text { Turobolem o piedras de fue- } \\
\text { go. }\end{array}$ \\
\hline Del Caladre & 4r Caladrius \\
\hline Du pelican & 4v Guivra. Se trata de la víbora \\
\hline
\end{tabular}

14 Manuscritos localizados y descritos en el recurso virtual bestiary.ca, a través de la URL http:// bestiary.ca/prisources/psmanu1886.htm (consultado el 10 de marzo de 2014). 


\begin{tabular}{|c|c|}
\hline Du Nicticorax & 5r Pelican \\
\hline De l'aigle & $\begin{array}{l}\text { 5v Tigre: Reproducimos la de- } \\
\text { finición : «Une bestie est qui est } \\
\text { apele tigres et est uns serpens. } \\
\text { Celle beste est de telle natures } \\
\text { que elle est furia et si crudelis } \\
\text { que nul homme vuiant ne los } \\
\text { habiter». Es la primera vez que } \\
\text { aparece el tigre definido como } \\
\text { una serpiente, posiblemente por } \\
\text { confusión con un reptil denomi- } \\
\text { nado tyro, sin embargo aquí no } \\
\text { aparece otra de las características } \\
\text { más conocidas de este mamífero } \\
\text { como es su rapidez. Únicamente } \\
\text { encontramos la confusión mamí- } \\
\text { fero-reptil en este bestiario y en } \\
\text { la versión catalana de los bestia- } \\
\text { rios toscanos. }\end{array}$ \\
\hline Del fenis & 5v Grues \\
\hline De la Hupe & $\begin{array}{l}\text { 6r Voultre. Otra vez se trata } \\
\text { de la víbora, en algunos textos } \\
\text { traducido como dragon -ejemplo } \\
\text { algunas versiones toscanas- En } \\
\text { este capítulo el reptil ataca los } \\
\text { hombres vestidos y en cambio } \\
\text { no se acerca a los desnudos. Esta } \\
\text { desnudez significa limpieza de } \\
\text { pecados. }\end{array}$ \\
\hline Du formi & $6 \mathrm{v}$ Aronde \\
\hline De la seraine & 7r Voltours. Ejemplo del diablo \\
\hline Du heriçon & $\begin{array}{l}\text { 7v Aspis. Reproducimos la } \\
\text { definción. «Physiologus nous dit } \\
\text { que il est une beste qui a non as- } \\
\text { pis et est uns serpens qui garda le } \\
\text { bausme...» Se trata del conocido } \\
\text { ejemplo del áspid vigilando el ár- } \\
\text { bol del que se extrae el bálsamo y } \\
\text { que para evitar ser distraída por } \\
\text { los cazadores, ensordece. }\end{array}$ \\
\hline
\end{tabular}




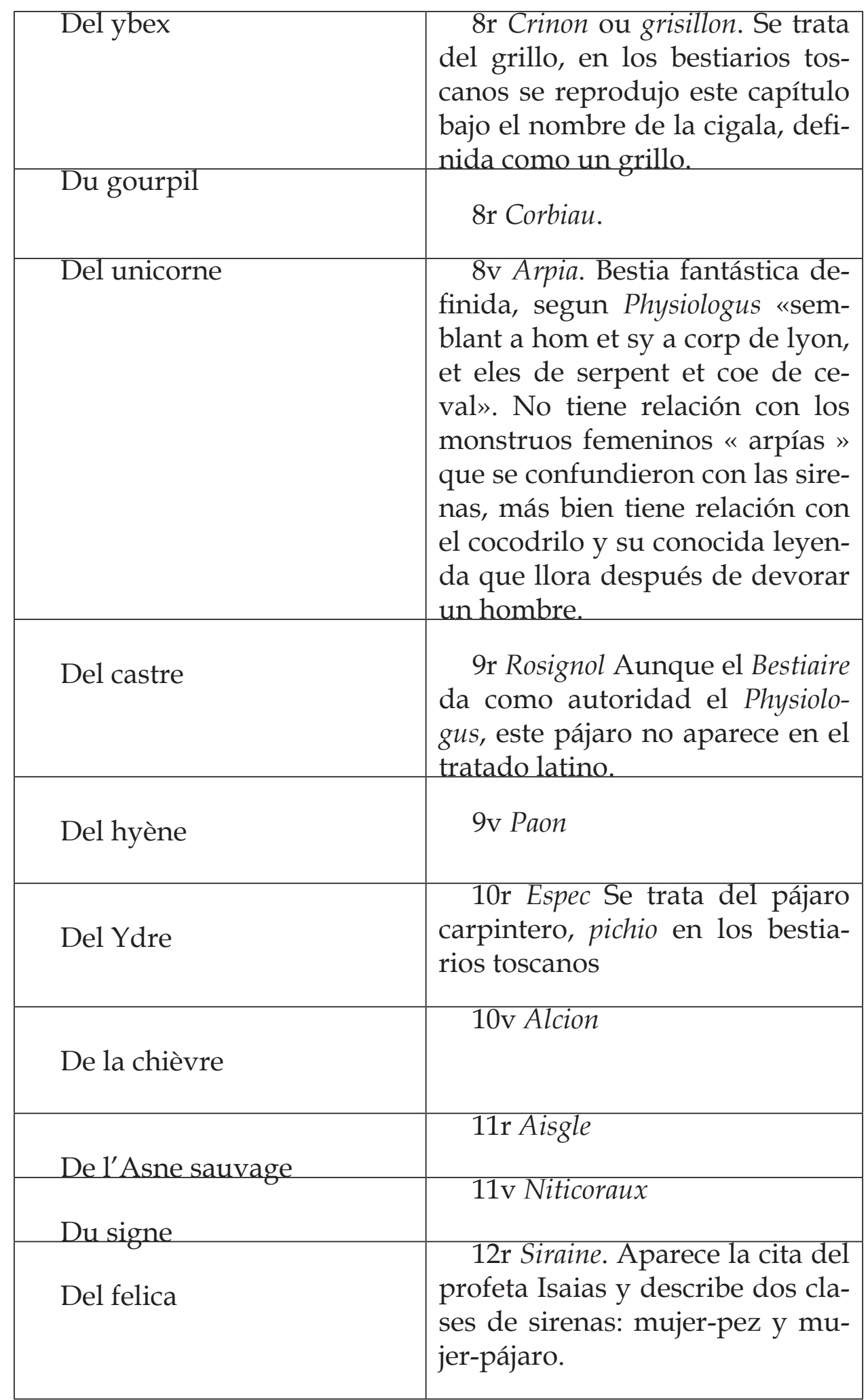




\begin{tabular}{|c|c|}
\hline De la panthère & $\begin{array}{l}\text { 12v Hupe. Se trata de la Upupa } \\
\text { latina. Animal que se caracteriza } \\
\text { por su extremo amor y cuidado } \\
\text { a los padres ancianos. Esta ca- } \\
\text { racterística dejo de atribuirse a la } \\
\text { upupa, ave de connotaciones ne- } \\
\text { gativas para pasar a ser atribuida } \\
\text { a la cigüeña. }\end{array}$ \\
\hline De la coine & $\begin{array}{l}\text { 13r Vasche. Incluye el relato - } \\
\text { que no aparece en el Physiologus, } \\
\text { aunque se de cómo autoridad- } \\
\text { de Argos el de los cien ojos y la } \\
\text { vaca. }\end{array}$ \\
\hline De la pertris & $\begin{array}{l}\text { 13v Fenis. Ave fantástica bien } \\
\text { conocida que representa la figura } \\
\text { de Cristo resucitado. }\end{array}$ \\
\hline De la mostoile & $\begin{array}{l}\text { 14r Papegay. Conocido por su } \\
\text { extrema limpieza y por la capa- } \\
\text { cidad de producir sonidos seme- } \\
\text { jantes a los humanos. }\end{array}$ \\
\hline De la asida & 14v Fourmis \\
\hline De la tortre & 15r Ostriche \\
\hline Du cerf & $\begin{array}{l}\text { 15v Herison } \\
15 \mathrm{v} \text { Ibeux }\end{array}$ \\
\hline De la Salemandre & 16v Goupil o reynart \\
\hline De la tanrine colour & $\begin{array}{l}\text { 17r Ragne Incluye la fábula de } \\
\text { la araña y de la mosca. Este ca- } \\
\text { pítulo se reproduce en los bestia- } \\
\text { rios toscanos }\end{array}$ \\
\hline Del olifant & $\begin{array}{l}\text { 17r Annes de la mer. Se trata de } \\
\text { un árbol que surge del mar y en } \\
\text { el que se posan aves marítimas, } \\
\text { nacidas del propio árbol. Estas } \\
\text { aves penden del árbol hasta que } \\
\text { mueren y caen al mar. Significa } \\
\text { que la misma manera que las } \\
\text { aves caen al agua, los cristianos } \\
\text { necesitan el agua del bautismo. }\end{array}$ \\
\hline
\end{tabular}




\begin{tabular}{|c|c|}
\hline De la chipèvre sauvage & 17v Basilicoc \\
\hline Del aimant & $\begin{array}{l}18 \mathrm{v} \text { Teris serpent. Se trata de un } \\
\text { reptil con el cuerpo cubierto de } \\
\text { pelo y muy rápido, posiblemente } \\
\text { de aquí viene la confusión con el } \\
\text { tigre mamífero. }\end{array}$ \\
\hline Du leu & 19r Unicornis o Monotheros \\
\hline \multirow[t]{13}{*}{ Du chien } & 19v Grifo \\
\hline & 20r Castoires \\
\hline & 20v Hienne \\
\hline & 21r Ulica o fullica \\
\hline & 21r Cocadrile et hydre \\
\hline & $\begin{array}{l}21 \mathrm{v} \text { Dorcon Se trata de una } \\
\text { especie de cabra, coincide con } \\
\text { algunos bestiarios latinos deri- } \\
\text { vados del De bestiis et aliis rebus, } \\
\text { pero no del Physiologus. }\end{array}$ \\
\hline & $\begin{array}{l}\text { 22r Manticora o Centicora. Bes- } \\
\text { tia fantástica muy cruel y salvaje }\end{array}$ \\
\hline & 22v Asne sauvage \\
\hline & 23r Singe (simio) \\
\hline & 23r Signe (cisne) \\
\hline & $\begin{array}{l}23 \mathrm{v} \text { Huliau. Se trata de un ave } \\
\text { que vive cerca de los cementerios }\end{array}$ \\
\hline & $\begin{array}{l}\text { 23v Pantera. Definida como } \\
\text { bestia de diversos colores, emi- } \\
\text { te un olor muy suave que atrae } \\
\text { todos los animales excepto el } \\
\text { dragón. Considerada imagen de } \\
\text { Jesucristo. }\end{array}$ \\
\hline & 25r Pertris \\
\hline
\end{tabular}


25v Covie. Bestia marina identificada con la ballena o aspischelone según el Physiologus. Se popularizó la historia de este enorme animal que confunde los marinos con una isla. El nombre de Covie o conie -en la versión corta- es bastante extraño ${ }^{15}$.

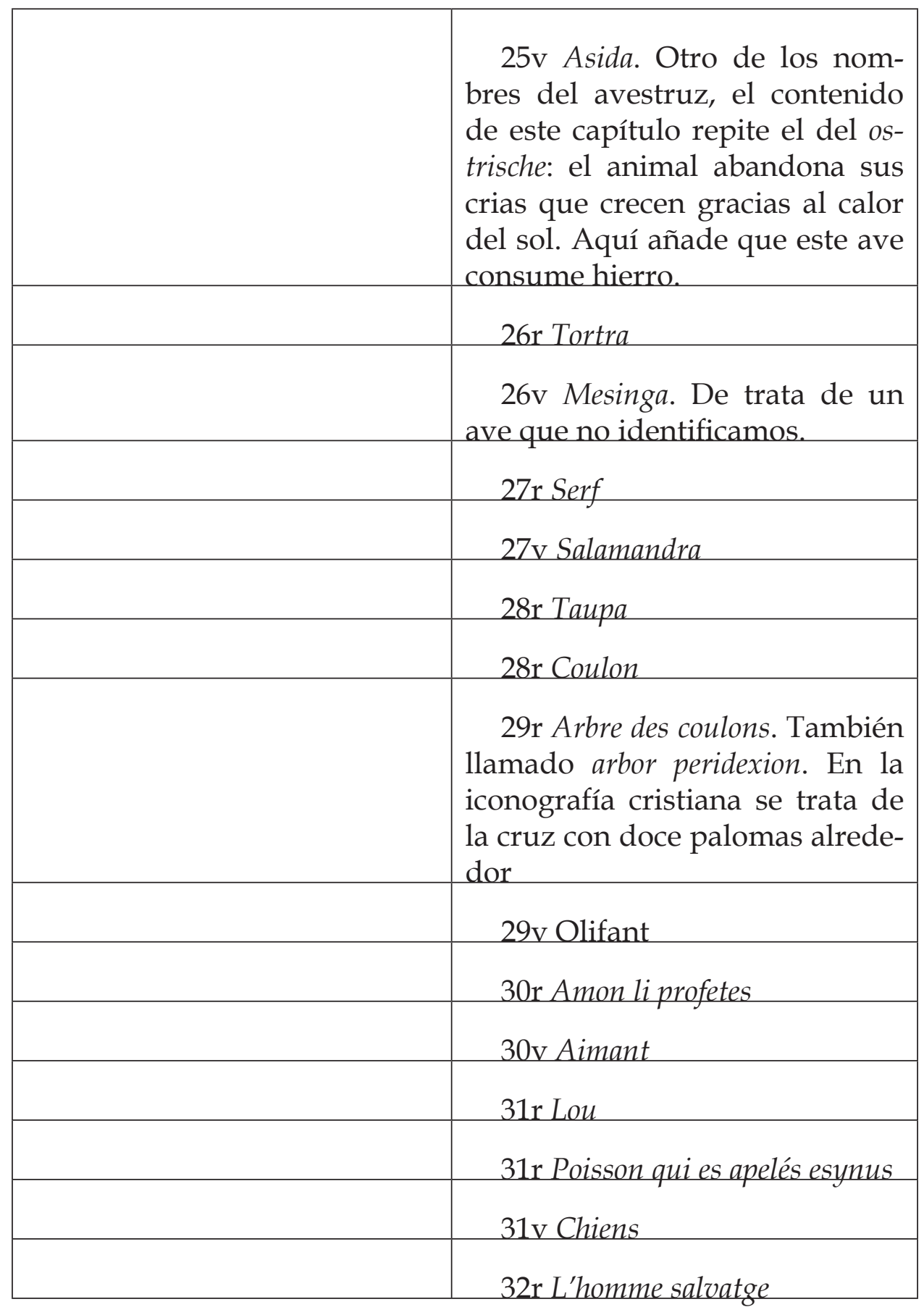

15 McCulloch 1956 i 1962. La autora cree que este extraño nombre se debe a la deformación del nombre maclovia o bestia de Saint Malo, donde se creía habitaba una ballena. 


\begin{tabular}{|l|l|}
\hline & $32 \mathrm{v}$ Merle \\
\hline & $33 \mathrm{r}$ Escoufle. \\
\hline $33 \mathrm{v}$ Muscalert. \\
\hline $34 \mathrm{r}$ Des quatre elements. \\
\hline $\begin{array}{l}35 \mathrm{v} \text { Orphanay, un ave proce- } \\
\text { dente de lándia }\end{array}$ \\
\hline $\begin{array}{l}36 \mathrm{r} \text { Explicit li gran bestiaire, } \\
\text { commencé par moi, Jehan Pa- } \\
\text { nier a Pous sainte Mexene et par- } \\
\text { cheve au chastau de Bouillenco- } \\
\text { net li lundi xviii jour de setembre } \\
\text { de mil iii C lxxv }{ }^{16}\end{array}$ \\
\hline
\end{tabular}

El Bestiaire d'amours atribuido a Richard de Fournival es un texto que trastoca la simbología animal de base alegorico-religiosa y se convierte en un tratado de didáctica amorosa a consecuencia, posiblemente, del intento de teorizar el discurso amoroso nacido de la ideología cortés nacida en la poesía occitana. El bestiario amoroso, datado aproximadamente el 1260 por Segre $(1957){ }^{17}$ pero parece ser que anterior al de Beauvais, como intenta demostrar Baker, ${ }^{18}$ recorre los diferentes estadios de la relación amorosa en boca de un caballero que compara, bien su propio estado de ánimo, bien la actitud de la dama, que se presenta casi divinizada, con las enseñanzas que le proporcionan los animales. Así, por ejemplo, leemos que todo enamorado necesita del poder del canto y de la palabra para ser escuchado, aunque teme morir en su canción, como el cisne. Por otra parte el autor se lamenta de la inconstancia de la dama y de

16 Explicit que nos indica la fecha de la copia y los datos del copista. El manuscrito Vat-Reg. 1323 (catalogado por Langlois, 1889), contiene además varios textos de carácter moral así como también de tema pseudocientífico. Entre las obras contenidas en este códice de gran valor, obtenemos: L'epistre d'Othea en verso y prosa, obra atribuida a Christine de Pisan; La natura des chiens, tratado de caza; Le livre des éches moralisés, obra de Jacques de Cessolis y de dos traductores Jean de Vignay y Jean Ferron; La breviaire des Nobles, fait par maistre Alain de Chartier.

17 Los estudios sobre el Bestiaire d'amours se centran en la recuperación de manuscritos y en las traducciones que generó a otras lenguas como la obra Lo Diretano Bando (Casapullo 1997), aunque se reconoce la importancia de textos texto en la configuración de textos posteriores (Radicula 1962, 576606; Bianciotto 1981, 107-117).

18 Según Baker, los capítulos que Pierre de Beauvais copió del Bestiario d'amour són los siguientes: víbora del capítulo 6, tigre, grua, voultre (nuevamente la víbora), buitre, cigala, cuervo, pájaro carpintero, pavo, la historia de Argus, avestruz, perro, topo. Esta comparación exhaustiva es parte de su trabajo de 2010 sobre la versión extensa del Bestiaire de Pierre de Beauvais (Baker 2010, 27-28). Sin embargo estos animales ya aparecen en el libro III del De bestiis et aliis rebus, de redacción anterior, siglo XII. McCulloch señala la extrañeza de los animales que componen este libro y que originan una segunda familia de bestiarios, diferente de los derivados de las antiguas versiones latinas del Physiologus, la principal fuente de los textos franceses en verso -y posiblemente de la versión corta del Bestiario de Pierre de Beauvais. 
su poder, como el león, que por su capacidad de resucitar a sus hijos se compara con la dama, capaz de dar o quitar la vida al enamorado. Desoir a la dama y evitar que el amor ataque los sentidos corporales es otro tema constante del Bestiaire, las comparaciones cinegéticas ilustradas con animales como el tigre o el unicornio, la seducción de la pantera, la prisión amorosa, la crueldad de la dama, la excusación del enamorado por sus faltas... Todos estos tópicos se entrelazan con ejemplos animales y constituyen un pequeño hilo argumental, por lo que el orden deja de ser el que generalmente presentan los textos animalísticos desde el antiguo Physiologus, encabezado por el león.

El hecho de utilizar la simbología animal en clave amorosa era uno de los recursos más importantes de la poesía trovadoresca. Las imágenes de la lírica de Rigaut de Berbezilh, ${ }^{19}$ por ejemplo, con su famoso poema sobre el elefante caído pasan a la lírica toscana y, posteriormente a la castellana y catalana (Martín Pascual 2012a, 150-154). Autores sicilianos como Giacomo da Lentini, Stefano Protonotario, Inghilfregi Siciliani, toscanos como Guido Guinizelli, Cino da Pistoia o Guido Cavalcanti fueron seducidos por la simbología animal y tuvieron el acierto de utilizarla en sus composiciones. Otros poetas como Chiaro Davanzati e incluso Petrarca utilizan ejemplos animales tan conocidos como la salamandra que vive del fuego, el basilisco que mata con la mirada, el fénix que renace de las cenizas, el áspid comparado con la dama que no atiende las súplicas del enamorado, el león que tiene la capacidad de resucitar a sus hijos como la dama al poeta, el cisne que muere cantando o la tigresa que se deja cazar por ver su imagen reflejada en unos espejos. La mayor parte de estos motivos los encontramos en la poesía trovadoresca, lo que evidencia un origen culto y una transmisión escrita.

\section{CONCOMITANCIAS CON LOS BESTIARIOS TOSCANOS Y CATALANES}

\subsection{Estructurales}

No cabe duda que tanto el Bestiaire de Pierre de Beauvais como el Bestiaire d'amours influyen en la configuración de los bestiarios toscanos y, a su vez, en los testimonios catalanes conservados. Éstos integran animales que no aparecían en los antiguos Physiologi pero, en cambio sí aparecen en Beauvais y, seguramente, su origen se remonta a los bestiarios extensos y enciclopédicos latinos. Por ejemplo coinciden insectos como la cigala -en el Bestiaire "grillo" pero con las mismas características; el tigre definido en los toscanos como un cuadrúpedo pero en la traducción catalana como una serpiente; el lobo, la araña, el perro. En cambio desaparecen para siempre animales como la antulla, tanto en el BdA como en los toscanos y las reminiscencias a elementos del

19 La poesía de Rigaut de Berbezilh y la razó que la precede tuvieron una gran difusión, llegando a constituir el argumento de una narración del Novellino. El relato de la vida del trobador explica que «se deletava molt en dire en sas cansos similitudines de bestias e d'ausels» (Riquer 1975, vol. I, 286). 
Lapidario como las piedras de fuego y el diamante.

Relación contenidos Bestiaire d'amour, bestiario toscano más antiguo y una de las versiones de los textos catalanes: ${ }^{20}$

\begin{tabular}{|c|c|c|}
\hline $\begin{array}{l}\text { Bestiaire } \\
\text { d'amours (Segre } \\
1957 \text { ) }\end{array}$ & Texto toscano (Vat. Chi M.VI.137) & $\begin{array}{l}\text { Versión A } \\
\text { catalana(Panunzio } \\
\text { 1964) }\end{array}$ \\
\hline \multirow[t]{4}{*}{ Prologo } & Proemio: & Proemio \\
\hline & La formica & Formiga \\
\hline & De la natura de l'apa & Abella \\
\hline & De la natura de lo rango & Aranya \\
\hline Coc (gallo) & De la natura del gallo & Gall \\
\hline $\begin{array}{l}\text { Asnes salva- } \\
\text { ges }\end{array}$ & De la natura del lupo & Llop \\
\hline Leu (lobo) & De la natura del asino & Ase salvatge \\
\hline $\begin{array}{l}\text { Crisnon (ci- } \\
\text { gala) }\end{array}$ & De la cicala & Cigala \\
\hline Cingne & De la natura del ciecino & Cigne \\
\hline $\begin{array}{l}\text { Chiens (pe- } \\
\text { rro) }\end{array}$ & De la natura del cane & $\mathrm{Ca}$ \\
\hline Leu $($ lobo, 2) & De la natura de la vipera & Vivra \\
\hline $\begin{array}{l}\text { Wivre (ví- } \\
\text { bora) }\end{array}$ & De la natura de la scimia & Simia \\
\hline $\begin{array}{l}\text { Cinge (si- } \\
\text { mio) }\end{array}$ & De la natura del corbo & Corb \\
\hline Corbel & De la natura de lo leone & Lleo \\
\hline I innc & Belula (comadreja) & Mostela \\
\hline Mustoile & Del Calandrusso & Calandrí \\
\hline
\end{tabular}

20 La clasificación de las familias de los textos toscanos es dificultosa por sus múltiples versiones. Los manuscritos conservados se pueden agrupar en dos familias, una más antigua que denominamos París-Roma (ms. conservados en Roma-Vaticana y BNF) y otra supuestamente más moderna con textos más extensos que denominamos R-N (textos conservados en las Bibliotecas Riccardiana de Florencia y Nazionale de Nápoles). Del estudio de estos manuscritos deducimos que el más antiguo es el ms. de la Biblioteca Vaticana Chigiano M. VI. 137 (Martín Pascual 2012a, 147-181). Por lo que respecta a los testimonios conservados de un bestiario catalán, traducción de alguna de las versiones toscanas correspondiente a la familia Paráis-Roma, dos manuscritos contienen un texto completo (a y B) con bastantes semejanzas, mientras que existen 4 fragmentarios (Martín Pascual 2012b y 2012c). El texto completo lo consultamos en la edición de Panunzio 1964. 


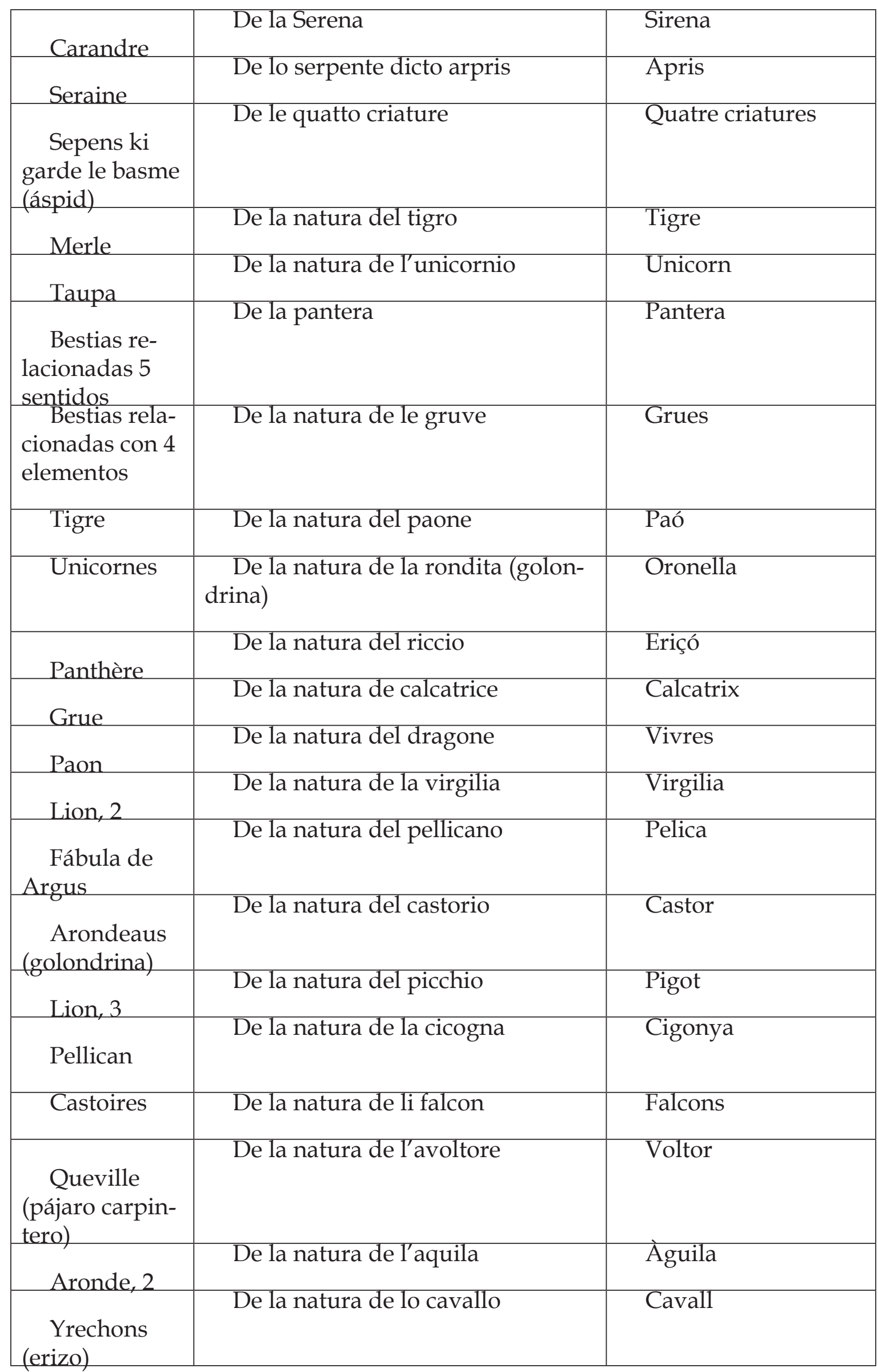




\begin{tabular}{|c|c|c|}
\hline Cocodrille & De la natura de li colonbi & Coloms \\
\hline Ydre & De la natura de lo strusso & Estruç \\
\hline Vipre, 2 & De la natura de la baliena & Balena \\
\hline $\begin{array}{c}\text { Singesse (si- } \\
\text { mia, } 2)\end{array}$ & De la natura de la volpe & Volp \\
\hline Serre & De la natura de la fenice & Fenis \\
\hline Torterele & De la natura del leofante & Elefant \\
\hline $\begin{array}{c}\text { Pertris } \\
\text { Ostrice } \\
(\text { avestruz) }\end{array}$ & De la natura del pappagallo & Papagai \\
\hline $\begin{array}{c}\text { Huple }(u p u- \\
\text { pa) }\end{array}$ & De la natura del serpente & Perdiu \\
\hline Aigle & De la natura del cervio & Esparver \\
\hline Olifant & Lo pelo del leofante & \\
\hline Balaine & Lo serpente alcuna volta & \\
\hline Voltoirs & Uno arbore (peridexion) & \\
\hline
\end{tabular}

Las observaciones anteriores nos llevan a la hipótesis que los textos de Pierre de Beauvais, el Bestiaire d'amours y los texto toscanos están en cierta manera relacionados, en primer lugar por su disposición en prosa a manera de diccionario animal, en segundo lugar por su carácter menos alegórico y en mayor medida moralizante, como pauta de comportamiento, en tercer lugar por la disposición de contenidos, que aunque no coincide exactamente, sí que observamos una cierta proximidad en el orden de aparición o incluso agrupación de las especies animales. Es significativo, por ejemplo la aparición del león en una posición no preeminente o la secuencia de animales gallo, asno salvaje, lobo, cigala, cisne, perro, víbora que encabezan el bestiario amoroso y se repite en los textos toscano y catalán, solo precedidos de la hormiga, la abeja y la araña.

\subsection{Contenido}

Referente a los bestiarios en verso, no podemos asegurar que influyeran en la con-

21 Algunos manuscritos de la tradición toscana acaban en este capítulo 44 al igual que la traducción catalana del bestiario toscano, si bien añade un número 45 dedicado a un ave de caza que no aparece en los originales como es el gavilán. Esto explica que animales de una tradición tan conocida como el ciervo o la tórtola no aparezcan en las traducciones catalanas, aunque su simbología se conocía igualmente. 
figuración de bestiarios posteriores como los toscanos, en prosa, y sus traducciones catalanas. En éstos últimos desaparecen los elementos minerales pero se conservan algunos vegetales como el peridexion o árbol de las palomas (no en el texto catalán pero sí en el toscano), el árbol místico de las palomas que representa en realidad la cruz, alegoría que encontramos en múltiples representaciones artísticas del cristianismo primitivo.

Alan Deyermond (2007, 119-131) destacó una similitud entre el contenido de una poesía de Corella y la imagen que se daba de las sirenas atribuible a Guillem de Thaun. Según el estudioso, sorprende la frecuencia de alusiones a animales en las poesías seglares de Corella y su proximidad tanto a las imágenes contenidas en la versión catalana del bestiario como a las de la versión catalana de la enciclopedia Libre del trésor. La poesía que destaca Deyermond és la Mort per amor:

Si en lo mal temps la serena be canta, io dech cantat, puix dolor me turmenta en tant estrem, que ma penssa's contenta de presta mort; de tot l'aldre s'espanta

El inicio de esta poesía se acerca al soneto 21 del marqués de Santillana:

En el próspero tiempo las serenas plañen e lloran recelando el mal, en el adverso, ledas cantilenas cantan e atienden el buen temporal. Mas, ¿qué será de mi, que las mis penas, cuytas, trabajos e largor mortal jamas alternan nin son punto ajenas?

El razonamiento es el siguiente: las sirenas, criaturas traidoras y feroces, cantan alegremente en la tempestad porque prevén que con el mal tiempo las naves se hundirán y los marineros morirán de forma que ellas tienen así comida abundante, mientas que con el buen tiempo lloran porque no obtendrán el botín deseado. Según Deyermond $(2007,125)$, esta actitud no aparece en los bestiarios catalanes ni en el Llibre del Tresor pero sí en el Bestiaire de Thaün:

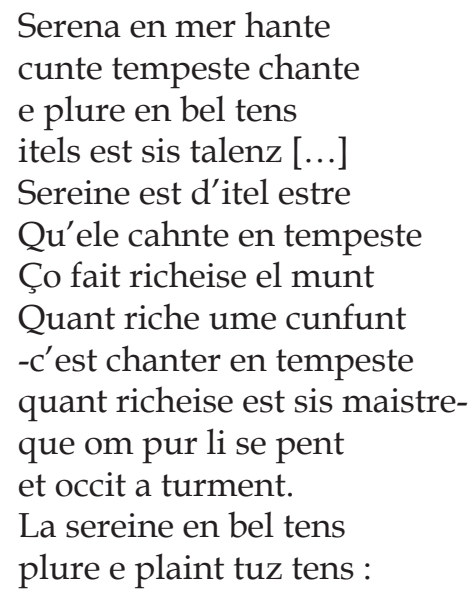


quant ome dune richeise

e put Dé la depreise

ilores est de bele ure

e la richeise pure

Más interesantes son las semejanzas de contenidos que encontramos en la introducción de animales agrupados como las "cuatro criaturas", pero también en descripciones como el tigre, el lobo y el perro.

Las cuatro criaturas a que se refieren algunos bestiarios son el resultado de la creencia que existen animales relacionados con los cuatro elementos: tierra, fuego, agua y aire, de los que toman su alimento. La primera vez que aparecen estas cuatro criaturas agrupadas es en la versión extensa de Pierre de Beauvais y en el Bestiaire d'amours, en ambos textos se trata de los siguientes animales: el topo relacionado con la tierra, la salamandra con el fuego, el camaleón con el aire y un pez o la rana con el agua. De todos estos pequeños animales solo la salamandra tiene una tradición procedente de los Physiologi latinos que la relacionan con el fuego, representa la castidad y la virginidad en las primitivas versiones, siempre una simbología positiva relacionada con los hombres justos y admirables. Con el tiempo, la figura de la salamandra mantiene esta atribución positiva, al compararse con los apóstoles en la festividad de Pentecostés pero también adquiere otra simbología menos alegórica y es comparada con los lujuriosos.

El tigre es uno de los animales más controvertidos. Esta fiera debía de resultar bastante extraña, un felino poco conocido como el león, el leopardo o la pantera. De él se nos dice que es un animal veloz, difícil de cazar y que para conseguirlo, se necesitan de unas trampas con espejos en los que la tigresa se refleja contemplando su belleza y olvida sus cachorros, momento que aprovechan los cazadores para llevárselos (Malaxecheverría 1982, 13-27). El nombre de este animal se ha relacionado con el río Tigris, habita en Armenia y significa saeta en esta lengua, siempre relacionado con la velocidad. El tigre no aparece en las versiones latinas del Physiologus pero sí en las Etimologías isidorianas y en el libro III del De bestiis et aliis rebus, de donde pasaría a las enciclopedias, al Bestiaire de Pierre de Beauvais y a los textos toscanos. La confusión con una serpiente se da precisamente en el texto de Beauvais, los toscanos no presentan esta confusión pero tanto la traducción catalana como alusiones a este animal en textos en esta lengua lo relacionan siempre con una serpiente (Martín Pascual 1995, 15-32). Por ejemplo, un sermón de san Vicente Ferrer perteneciente a su período de predicación en Castilla (Cátedra 1994, 399), en el que compara la actitud de la tigresa con la fijación por las riquezas temporales:

Sabed qué dize el libro De propietatibus rrerum. ${ }^{22}$ Cuenta que hay una natura de víbo-

22 Se refiere al tratado De proprietatibus rerum de Bartolomé de Glanville, una enciclopedia de contenido natural del siglo XIII muy popular y seguramente fuente de textos posteriores como el Livre dou Tresor de Brunetto Latini. 
ras que ha nonbre tigris e son buenas para fazer melezinas. E quando son grandes, non las pueden tomar e los que las toman para fazer las melezinas aguardan quando son pequeñas e toman un espejo grande e rredondo e liévanlo a la tierra donde están, e aguardan quando la tigris non está en el nido, e tómale los fijos e cabalga en un cavallo muy apriesa, e echa a foyr por el miedo de la madre, ca si lo sintiesse, auque fuesse a media legua, lo alacançaria: tanto corre la tigris. E quando viene la tigris, que non falla los sus fijos va en pos del omne por lo alcançar. E quando ella llega al espejo, míralo e vee allí la su ymagen e piensa que son los fijos, e párase e ponles la tecta por que mamen. E entre tanto, el otro pónese a salvo. E desque ella está assi un rrato, véese engañada, porque toma la ymagen de la cosa por la cosa, e tórnase.

El lobo se considera generalmente como un animal negativo, conecta con la idea de destrucción y aniquilamento por los continuos ataques que causa contra el hombre y los animales domésticos. Es también un símbolo monstruoso y irracional que se manifiesta en la licantropía, cuyo origen es el mito de Lycaon convertido en lobo (Metamofosis, I, 237). Nos encontramos con una especie animal no genuina del Physiologus y, por lo tanto su genealogía hay que buscarla en los naturalistas clásicos y en la interpretación que se difundirá por los bestiarios y enciclopedias. Según Plinio (VIII, 22) el lobo puede dejar un hombre sin voz si el animal lo mira primero, se considera un animal poco lujurioso ya que tiene un período sexual de 12 días, ahora bien, un pelo de la cola de este mamífero se considera un talismán amoroso, y finalmente, el buen lobo es el que solo come tierra. Plinio también recoge las transformaciones de hombres-lobo pero las considera ficciones. Aristóteles insiste en la idea del escaso período fértil de las hembras de los lobos.

San Isidoro (Etimologiae XII, 2, 23) ${ }^{23}$ introdujo la figura del lobo en los bestiarios posteriores, así como también la característica de la rapacidad creando incluso una etimología del nombre cercana a la del león ya que son animales con algunos puntos comunes, como por ejemplo la idea que el lobo muerde su propia pata cuando hace ruido sin querer, de la misma manera que el león borra sus huellas para no ser reconocido. En tratados posteriores se incrementa la idea de la agresividad del lobo, su rapacidad y su desmedida voracidad, se otorga el nombre de loba a las meretrices y gana la consideración de figura diabólica. En los bestiarios de tradición francesa encontramos el lobo en las dos versiones del de Pierre de Beauvais, y de nuevo en el Bestiaire d'amours, que presenta una detallada descripción: En primer lugar el texto amoroso recupera la idea antigua, procedente de Plinio, de la pérdida de la voz o la fuerza del hombre si el animal lo percibe primero, pero en el caso que sea el hombre quien descubra al lobo es el animal el que pierde su fuerza, de la misma manera que el enamorado pierde la fuerza ante la dama, por buscar una secuencia amorosa comparable. El mismo texto francés compara el amor de la dama con tres características del lobo: la imposibilidad

23 Citado a través de MacCulloch (1962, 188-189). 
de girar el cuello si no lo hace todo el cuerpo -igual que la dama que solo se entrega al amor de manera total; el hecho que el animal no coge sus presas si se encuentran cerca -el amor de la dama crece cuando el enamorado está lejos de ella; y la tercera que se refiere a la autoagresión del lobo para evitar hacer ruido y ser percibido, actitud que recuerda la virtud de la corrección.

Los bestiarios catalanes recogen todas estas peculiaridades y otorgan a cada una su correspondiente moralización, ciertamente original porque es un animal carente de tradición moralizadora. Sin embargo la más destacable es una referida a la loba popularizada gracias al Bestiaire d'amour y que reencontramos en el Espill de Jaume Roig: la hembra del lobo tiene tendencia a escoger de entre los machos al peor, hecho recriminable para una falsa dama que no merece los desvelos del caballero y característica que Jaume Roig atribuye a la madre de su protagonista, una mujer que expulsa a su hijo de casa porque ha encontrado el peor de los amantes. Según el Libre del Tresor: «quan ve el temps de lujuria molts mascles segueixen la femella e li van tots entorn però a la fi la loba guarda a tots e tria lo pus dolent e lo pus leis, que jagua ab ella, e jassio que tot l'any no s junten sino 12 vegades» (Wittlin 1976, 99). El capítulo del lobo en el Bestiari catalán es uno de los más extensos y que más valoraciones morales contiene. Las referencias literarias del lobo se relacionan con la rapacidad, el engaño o el amor brutal, como nos recuerda la poesia número 4 de Ausiàs March: "el cos ab la seua complexio / ha tal amor com un llop o renart/ que llur poder d'amar és limitat".

Finalmente, dedicaremos unas líneas al perro, animal conocido por su extrema fidelidad como animal de compañía, valioso vigía de la casa aunque en sus orígenes, por su proximidad al lobo también se considera un animal temible y monstruoso -el Can Cerbero que guarda las puertas del infierno.

La fidelidad del perro es un tema bien conocido por las narraciones folklóricas en las que encontramos que esta extrema actitud le supone incluso la muerte, como recordamos por el motivo de «Llewellin y su perro», incorporado en un cuento del Calila e Dimna y también en la versión catalana del Llibre dels Set savis de Roma. La fidelidad era una característica conocida y comentada por los autores clásicos (Plinio VIII, 40) aunque Aristóteles comienza a popularizar otra: la prudencia del animal que, cuando se sabe enfermo, ingiere diferentes hierbas para provocar el vómito y curar sus males.

Como no se trata de un animal propio del Physiologus, pasa a los bestiarios posteriores gracias a las Etimologiae isidoriana que destacan la fidelidad, la fuerza y la velocidad. Los bestiarios latinos y las enciclopedias dedican extensos capítulos a la descripción de las razas caninas, se incluyen ejemplos de estos animales y destacan sus propiedades, evidentemente la fidelidad. La imagen de los canes que pasa al bestiario catalán posiblemente se debe al Bestiaire d'amours el cual, no destaca la virtud de la fidelidad sino que prefiere referir una cualidad negativa aplicada al contexto amoroso: «Car se jou puisse faise ausi comme li chiens, ki est de tel nature ke quant il a vomi, k’i 
repaire a son vomite et le remengüe, jou eüse volentieres me proiere rengloutie cent fois, puis k'ele me fu volee des des» (Segre 1957, 15). El texto catalán no olvida la virtud positiva de la fidelidad que el buen cristiano tiene que mantener hacia Jesucristo como salvador del mundo. Si el can ingiere unas hierbas para provocar el vómito se considera que es un buen referente para el cristiano que confiesa sus pecados aunque, como hemos visto en la versión amorosa esto es signo de insistencia y error en mantener la relación amorosa, ${ }^{24}$ censurable en el caso de Curial ya que olvida a su querida Güelfa para fijarse en la tentadora Laquesis, actitud que le es recrimina por el sabio Melchor de Pando: «Tornits a Laquesis com los cans al vomit» (Curial e Güelfa, 2011, 398).

\section{CONCLUSIONES}

La simbología animal está presente en multitud de textos medievales de diferente índole: poéticos, narrativos, didáctico-moralizantes. Su estudio comprende un extenso arco de posibilidades, interpretaciones y concomitancias. No en vano, los animales tienen un lugar preeminente en el orden de creación de las especies, se estudia su naturaleza, se busca su utilidad pero también se aprovecha como ejemplo de conducta en una sociedad que ha admirar la obra de la creación pero al mismo tiempo ha visto cómo se corrompen actitudes humanas y el ejemplo animal -irracional pero con instinto natural- puede dar una lección.

Estas reflexiones consituyen el contenido de los bestiarios medievales, textos muy heterogéneos pero con el denominador común de ofrecer una ejemplaridad. Los bestiarios franceses, constituyen el grupo de textos más primitivo de la tradición animalística románica de los cuales derivarán bestiarios posteriores. Des las primeras manifestaciones en verso, textos concebidos como un simple roman, a los bestiarios en prosa, auténticos diccionarios de animales, el interés por el mundo animal se incrementa considerablemente y de ahí las adiciones de nuevas especies y su utilización en todos los ámbitos literarios. Podemos decir, pues, que los bestiarios en prosa franceses contribuyeron, tanto desde el punto de vista religioso-moral como amoroso, a incrementar el interés por la simbología animal en la literatura medieval.

\section{Bibliografía}

Angremy, A. (1983): «La Mappemonde de Pierre de Beauvais», Romania, 104, 316-350 y $457-498$.

Baker, C. (2005): «De la paternité de la Version longue du Bestiaire, attribuée à Pierre de Beauvais», Bestiaires médiévaux. Nouvelles perspectives sur les manuscrits et les tra-

24 En última instancia, esta referencia proviene de la Bíblia, Proverbios, 26.11. 
ditions textuelles. Communications présentées au XVe colloque de la Société internationale renardienne (Louvain-la-Neuve, 19-22.08.2003), ed. B. Van den Abeele, Louvain-laNeuve, Publications de l'Institut d'études médiévales de l’Université catholique de Louvain, 1-29.

Baker, C. (2009) : «Retour sur la filiation des bestiaires de Richard de Fournival et du pseudo-Pierre de Beauvais», Romania, 127:1-2, 58-85.

Baker, C. A. (2010) : Le bestiaire. Version longue attribuée à Pierre de Beauvais. Édité par Craig Baker, Paris, Champion [Les classiques français du Moyen Âge, 163], 2010.

Berkey, M. L., Jr. (1961) : Pierre de Beauvais: A Study of his Work with Critical Editions of his 'Vie de Saint Germer,' 'Vie de Saint Josse,' 'Translation et Miracles de Saint Jacques,' and 'Olympiade', Ph.D., University of California, Berkeley.

Bestiario de Oxford (1983), Bestiario de Oxford, facsímil del ms. Ashmole 1511, traducción de Carmen Andreu, estudio codicológico de Xènia Muratova, Madrid, Ediciones Arte y Bibliofília.

Bestiario de Cambridge (1974), Il Bestiario di Cambridge, edizione di Silvia Ponzi, introduzione di Francesco Zambon, presentazione di Umberto Eco, Milano, Ricci editore.

Bianciotto, G. (1980) : Bestiaires du Moyen Âge, mis en français moderne et présentés par Gabriel Bianciotto, Paris, Stock (Moyen Âge).

Bianciotto, G. (1981) : «Sur le Bestiaire d'Amour de Richard de Fournival», en Epopée animale, fable and fabliau. Actes du IV Colloque de la Societé Internationale Renardienne, Paris, 107-117

Cahier, C. y Martin, A. (1851) : «Le Physiologus ou Bestiaire», Mélanges d'archéologie, d'histoire et de littérature, 2, 1851, 85-100, 106-232; t. 3, 1853, 203-288; t. 4, 1856, 55-87.

Carmody, F. J. (1939) : Physiologus Latinus. Versio B. Éditions préliminaires, Paris, Droz.

Carmody, F. J. (1941): Physiologus Latinus, versio Y, «University of California Publications in Classical Phylology», XII, 95-134.

Cátedra, P. M. (1994): Sermón, sociedad y literature en la Edad Media. San Vicente Ferrer en Castilla (1411-1412), Salamanca, Junta de Castilla y León.

Curial e Güelfa (2011): Curial e Güelfa, edició crítica i comentaris de Lola Badia i Jaume Torró, Barcelona, Quaderns Crema.

Lo Diretano Bando (1997), Lo Diretano Bando edición. y estudio de Rosa Casapullo, Florencia.

Deyermond, A. (2007): «Las imágens del bestiario en la poesía de Joan Roís de Corella», en Poesía de Cancionero del siglo XV, ed. de Rafael Beltrán, José Luis Canet y Marta Haro, Valencia, Universitat de València, 119-131. [Publicado anteriormente en Homenaje al profesor José Fradejas Lebrero, Madrid, 95-106.]

Druce, G., tr. (1936): The Bestiary of Guillaume le Clerc, G. Claridge Druce (trad.), Ashford.

Dupuis, M., et Louis, S. (1988) : Le Bestiaire, téxte integral traduït en français modern, Paris, Lebaud Editor.

Fisiólogo = Pseudo Aristóteles, Fisiognomía. Anónimo, Fisiólogo, T. Martínez Manzano y C. Calvo Delcán (trads.), Madrid, Gredos, 1999.

Fradejas Rueda, J. M. (2005): El Bestiario de Juan de Austria, en Bestiaires médiévaux. Nouvelles perspectives sur les manuscrits et les traditions textuelles, Badouin Van den Abeele (ed.), Louvain la Neuve, 127-140.

Hippeau, C. ([1852] 1970) : Le bestiaire divin de Guillaume, clerc de Normandie, trouvère du XIIIe siècle publié d'après les manuscrits de la Bibliothèque nationale, avec un introduction sur les bestiaires, volucraires et lapidaires du moyen-âge, considérés 
dans leurs rapports avec la symbolique chrétienne, dans Mémoires de la Société des antiquaires de Normandie, Genève, Slatkine, 19 (2e série, 9), 317-476.

Hogan Cottin-Bizonne, S. (2005): Une Nouvelle edition du 'Bestiaire' de Philippe de Thaon (École nationale des Chartes, 2005). Consultado un resumen de la tesis a a través de la URL http://theses.enc.sorbonne.fr/2005/hogancottin

Kappe, A. H (1944): «The Historical Background of Philippe de Tahün's Bestiaire» Modern Languages Notes, LIV.

Langlois, E. (1889) : Manuscrits français e provençaux a Rome, Paris.

Mann, M. F. (1884): «Der Physiologus des Philipp von Thaün und seine Quellen», Anglia, VII, IX, 1884, 420-468; 1886, 391-434 \& 447-450.

Mann, M. F. (1888) : Der Bestiaire divin des Guillaume le Clerc, éd. M. Fr. Mann, Heilbronn, (Franz. Stud., VI, Heft II).

Mc Culloch, F. (1962): Medieval Latin and French Bestiaries (Chapel Hill: University of North Carolina Press, 1962; Series: Studies in the Romance Languages and Literatures, 33)

Martín Pascual, Ll. (1995): «El tigre convertit en serp i la tigressa emmirallada. Notes sobre la configuració dels bestiaris catalans», Estudis de Llengua i Literatura catalanes = Miscel lània Germà Colón, 3, Barcelona, Publicacions de l'Abadia de Montserrat, 15-32.

Martín Pascual, Ll. (2012a): «La tradición animalística en Italia: el Bestiario toscano», Cultura Neolatina, LXXII, 1-2, 147-181.

Martín Pascual, Ll. (2012b): «Nuevas aportaciones sobre la transmisión del Bestiari catalán», Revista de Literatura Medieval, XXIV, 155-179.

Martín Pascual, Llúcia (2012c): «Errores y divergencias en la traducción: las fuentes del Bestiari catalán», Critica del Testo, XV,1, 39-71.

Meyer, P. (1872) : «Le Bestiaire de Gervaise», Romania, I, 420-443.

Mermier, G. (1977) : Le bestiaire de Pierre de Beauvais (version courte). Édition critique avec notes et glossaire par Guy R. Mermier, Paris, Nizet.

Morini, L.(1996) : Bestiari medievali, Torino, G. Einaudi Editore, Series: I millenni.

Ovidio Nason, P. (1996): Les Metamorfosis, traducció de Jordi Parramon, Barcelona, Qauderns Crema.

Panunzio, Saverio (ed.) (1963-1964): Bestiaris, 2 vols. Barcelona, Barcino.

Plinio (1952) : Naturalis Historia, Paris, Les Belles Letres.

Radicula, C. (1962) : «Il Bestiaire d'Amours capostipite di bestiari latini e romanzi», Studi Medievali, III, 2, 572-606.

Raynard, G. (1885) : Poème moralisé sur les propietés des choses , Romania, XIV, 442-484.

Rebuffi, C. (1978) : «Il Bestiaire di Pierre de Beauvais», Medioevo romanzo, 5:1, 34-65.

Reinsch, R. (1890): Le bestiaire. Das Thierbuch des Normannischen Dichters Guillaume le Clerc zum ersten Male vollständig nach den Handschriften von London, Paris und Berlin, mit Einleitung und Glossar herausgegeben von Dr. Robert Reinsch, Leipzig, Reisland (Altfranzösische Bibliothek, 14).

Riquer, M. de (1975): Los trovadores. Historia literaria y textos, 3 vols, Barcelona, Planeta.

Sbordone, F. (1936): Physiologi graeci. Singulas variarum aetatum recenciones codicibus fere omnibus tunc primum excussis collatisque, Medionali, Genuae, Romae, Napoli, 1936 [reproducción anastática Hildesheim-Nueva York, Georges Olms Verlag, 1976.]

Segre, C. (1957) : Li bestiaires d'amours di Maestre Richard de Fournival e li response du Bestiaire, Milano-Napoli.

Villar Vidal, J, y Docampo Álvarez, P. (2003): El Physiologo latino, versión B. I. Introduc- 
ción y texto latino, en «Revista de Literatura Medieval», XV, 9-52.

Walberg, E. (1900) : Le Bestiaire de Philippe de Thaün, Paris and Lund: H. Welter/ H. Moller.

Walpole, Ronald N. (1951): «Charlemagne's Journey to the East: the French translation of the legend by Pierre of Beauvais », Semitic and Oriental Studies: A Volume Presented to William Popper on the Occasion of his Seventy-Fifth Birthday October 29, 1949, éd. Walter J. Fischel, Berkeley et Los Angeles, University of California Press (University of California Publications in Semitic Philology, 11), 433-456.

Wittilin, C. J. (1971-89): Llibre del Tresor, 4 vols., traducció catalana de Guillem de Copons, Barcelona, Barcino.

Zambon, F. (1975): Il Fisiologo, Milano, Adelphi. 